\title{
Trade-off between Accuracy and Longevity in Wireless Sensor Networks
}

\author{
N. Laloo, M. S. Sunhaloo, and R. K. Subramanian
}

\begin{abstract}
Two major controversial metrics that determine the stability period of a wireless sensor network (WSN) are accuracy and longevity. In this paper, we analyse the trade-off between accuracy and longevity in WSNs. We investigate different types of WSNs routing techniques together with their applications and state of the art in WSN routing protocols and determine their underlying success with regards to accuracy and longevity. We provide alternatives for algorithms not described in both parameters.
\end{abstract}

Index Terms-Network lifetime, routing protocol, wireless sensor network.

\section{INTRODUCTION}

Wireless Sensor Networks (WSNs) is an active field of research because of the limitations of the networks at gathering information in inaccessible region. Sensor nodes have limited transmission range, processing, storage capabilities and energy resources. The networks remain useful as long as there are alive sensor nodes. Much emphasis is being placed at prolonging the network lifetime. However, in some cases extending the lifetime may jeopardise accuracy of the entire network.

In this paper, we investigate different types of WSNs with regards to accuracy and longevity. In Section II, the different types of WSNs routing techniques are discussed. Routing algorithms that enhance the performance of the networks are described in Section III. In Section IV, we define accuracy and longevity as the performance metrics and we analyse the different protocols with respect to accuracy and longevity in Section V. Finally in Section VI we provide a trade-off between the performance metrics.

\section{Classification OF Wireless Sensor Networks ROUTING TECHNIQUES}

Throughout literature, routing protocols are classified in one of the following categories; flat network architecture, hierarchical, or adaptive routing architecture [1]. In Flat routing architecture, all nodes are considered as peer. This type of architecture often involves minimal overhead for

Manuscript received March 14, 2014; revised May 16, 2014.

N. Laloo is with the Department of Industrial Systems Engineering, School of Innovative Technologies and Engineering, University of Technology, Mauritius (e-mail: n.laloo@umail.utm.ac.mu).

M. S. Sunhaloo is with the School of Innovative Technologies and Engineering, University of Technology, Mauritius (e-mail: ssunhaloo@umail.utm.ac.mu).

R. K. Subramanian was with the Department of Computer Science, Faculty of Engineering, University of Mauritius (e-mail: rksuom@yahoo.co.in). maintenance, and caters for fault tolerance mainly by adopting multiple routes between communicating nodes. Hierarchical routing architecture imposes a structure to achieve energy efficiency, stability and scalability. Nodes are organized in clusters with some nodes having more energy and higher responsibilities in terms of communication compared to other nodes. This type of routing structure has the potential to reduce energy consumption consequently extending the lifetime of the network. Adaptive routing architecture may further be broken down into data centric approach or location based routing. In adaptive routing certain parameters may be controlled to adapt to current network conditions. Data centric use mainly attribute based naming whereby a source node queries an attribute for the phenomenon rather than an individual sensor node. Location based routing on the other hand use location to address a sensor node. It is useful in applications where position of the node is relevant to the query initiated by the source node.

\section{EFFICIENT Routing AlgorithMS}

The working of state of the art routing algorithms falling under the different classifications of WSN routing techniques mentioned in Section II are investigated as follows to determine their effectiveness based on accuracy and longevity.

\section{A. Flat Routing}

Algorithms: Directed diffusion, SPIN-PP, SPIN-EC, SPIN-BC, SPIN-RL, SPIN-M, Rumor routing, SER, GBR, COUGAR, ACQUIRE, SAR (Sequential Assignment Routing), EAR

\section{B. Hierarchical Routing}

Algorithms: SHRP, LEACH, PEGASIS, Hierarchical PEGASIS, EB PEGASIS, HEED, TEEN, APTEEN, GAF

\section{Adaptive Routing, Data Centric, Location Based}

\section{Algorithms: MECN, SMECN, GAF, GEAR}

Directed diffusion is a data centric protocol. Task descriptions are represented in directed diffusion as a series of attribute-value pairs [2]. The task description describes interest for data matching the attributes. The interest is dispersed into the network by flooding with a low event data rate. The receiving nodes cache the interest and gradients are set up towards the sink node. Reinforcement is sent for single or multiple paths. The source then forwards high rate data to high gradients link along reinforced paths.

The Sensor Protocols for Information via Negotiation (SPIN), SPIN-PP, proposed by Heinzelman, Kulik and Balakrishnan [3] is a simple protocol using three-stage 
handshake for distributing data in a network. The protocol design is based on cooperation and resource adaptation. Communication in SPIN is carried out through three kinds of messages. The new data advertisement, ADV, message which contains a meta-data is sent when a node wants to share data. The Request for Data, REQ message is forwarded when a node accepts to receive data and the data message. The DATA is build up with the actual data with a meta-data header. The SPIN protocol aims mainly at reducing implosion, overlapping and resource blindness. Implosion is reduced through the negotiation process. The use of meta-data helps to eliminate overlapping since the portion of data of interest is named. SPIN-PP is adapted mainly for point to point communication where nodes may communicate directly.

Heinzelman, Kulik and Balakrishnan [3] proposed SPIN-EC, which is an improved form of SPIN-PP with energy conservation heuristics. When the energy level of the nodes is high, SPIN-EC uses the three-stage protocol of SPIN-PP for communication. Gradually, with decreasing energy level, SPIN-EC decreases its contribution. In SPIN-EC, the nodes initiate an action only if they have enough energy to complete the remaining stages without depleting their energy. Thus on receipt of an ADV message, a node does not send an REQ message if it lacks energy to perform request and receipt of data.

The SPIN-BC protocol as proposed by Heinzelman, Kulik and Balakrishnan [3] uses a single shared channel for communication. The channel ensure that the message is received by the nodes within a certain region from the sender irrespective of the destination node. Thus with only one transmission the neighbours of a node may receive a message. A node having data to send needs to check the channel until it is idle before sending a message.

The SPIN-RL is an improved and more reliable version of SPIN-BC proposed Heinzelman, Kulik and Balakrishnan [3]. The SPIN-RL protocol ensures receipt of requested data by keeping track of the different advertisements from the different nodes. Moreover, the SPIN-RL protocol restricts the frequency between sending and resending of data. Before resending data, SPIN-RL halts for specific time period.

The SPIN-M protocol as proposed by Rehena, Roy and Mukherjee [4] improves on the SPIN family of protocols including SPIN-PP, SPIN-BC, SPIN-RL, and SPIN-EC. The SPIN-M makes use of the ADV, REQ and DATA messages similar as in the SPIN family of protocols. However, the SPIN-M protocol includes a distance discovery phase to calculate the distance of each node from the sink node in terms of hops. The SPIN-M protocol uses the hop distance to carry out negotiation for data transmission

Rumor Routing introduced by Braginsky and Estrin [5] is a technique of forwarding queries to nodes with data of particular event. Data is retrieved mainly with respect to the event instead of the network addressing scheme or geography. Instead of flooding the query throughout the entire network as with directed diffusion, a single walk through path to the event may be sought. Rumor routing considers the network as a group of widely and densely distributed wireless sensor nodes, which are within relatively short and symmetric radio ranges. Each node maintains a list of events in an event table and a list of neighbours. The nodes update their event table upon detection of new events and probabilistically generate agents, which are long-lived packets, which travel and propagate information in the network. The algorithm also favours the use of agents, which are long-lived packets that are forwarded across the network. The use of agents allows nodes to have information about nodes that have perceived a particular event.

The Stream Enable Routing (SER) Protocol introduced by Su and Akyildiz [6], allows the sources to select routes based on instruction by the sink. The SER protocol consists of seven phases, the source discovery, the route selection, route establishment, route reconnection, I-message transmission, instruction update and task termination. The protocol makes use of different message types to carry out its tasks.

Powell, Jarry, Leone and Rolim [7] devised the Gradient-Based Routing, (GBR) algorithm, which improves on gradient-based routing by combining direct and multi-hop transmission in terms of energy load balancing amongst the nodes. The authors referred to improvement based on stochastic path selection and spreading techniques including energy based and stream based adjustment to the height. However, Powell, Jarry, Leone and Rolim [7] focused on the fact that nodes found near the sink quickly deplete their energy. They introduced a static potential function for each node. The protocol adopts a mixed strategy such that if the neighbouring node has a higher potential the data is routed to it for ultimate routing to the sink. However, if the neighbouring node is more limited in resource than the current node, the node transmits the data to the base station without relaying it.

The network under the COUGAR approach is viewed as a distributed database [8]. The motivation behind COUGAR design is mainly to favour the querying of the networks and allowing in-network processing. COUGAR allows interaction between the routing layer and the application layer by including a query proxy layer. The gateway node includes a query optimiser to produce query-processing plans on receipt of queries from outside. The query plan identifies the communication among sensors and the processing under different modes.

In Active Query Forwarding in Sensor Networks (ACQUIRE) proposed by Sadagopan, Krishnamachari and Helmy [9], the wireless sensor network is viewed as a distributed database. Under ACQUIRE, the node in the network forwards an active query packet. Neighbouring nodes help update the packet in the event that it is obsolete. The node selects neighbouring node at random to further spread the query. The query is progressively resolved into smaller components as it moves into the network. The solved query finally reaches the querying node.

Sequential Assignment Routing (SAR) considers QoS issues for routing decisions. It provides a table driven multipath approach. A priority level is associated with each packet. The links and routes considered are related to delay and energy cost which characterize their QoS. In the event of failure of the active nodes, the protocol recalculates the routes. The objective of SAR is to improve the lifetime of the network by minimizing the average weighted QoS metric.

Energy and Activity Aware Routing (EAR) [10] protocol 
is an online routing protocol, which operates by analysing the activity pattern from an Activity Transition Probability Graph (ATPG) and the energy balance to choose its next hop relay node. EAR increases network lifetime by maintaining an energy balance across the nodes in the network, at the same time meeting application performance with desired throughput and low data delivery latency.

The Simple Hierarchical Routing Protocol (SHRM) proposed by Barenco Abbas, González, Cardenas and García Villalba [11] aims mainly at extending the network lifetime based on energy level, number of hops and link quality as the three main metrics for best route detection. The algorithm includes load-balancing techniques to ensure that uniform distribution of traffic along the possible routes. SHRM includes flexibility and uses the specific unifying protocol, SP, of TinyOS operating system, which allows protocols to select their neighbours based on information from the link layer [12]. The SHRM protocol ensures regular monitoring of the battery lifetime and link quality. Nodes that cannot contribute to good topology connection are removed from the routing table. The protocol considers the minimum threshold proposed by IEEE LQI indicator to cut off neighbour nodes with average link quality from the routing table [13].

In the Low Energy Adaptive Cluster Hierarchy Routing Protocol (LEACH), proposed by Heinzelman, Chandrakasan, and Balakrishnan [14], the network is organised as clustered. The node selected as the cluster head is rotated amongst the nodes in the network to balance energy consumption. The protocol operates in phase such that in the setup phase, the cluster head selection is done and in the steady phase data communication is done. The cluster head establishes TDMA scheduling for communication in its cluster, during which time, normal nodes may switch off their interfaces. The cluster head contributes to remove redundancy by doing data aggregation of the nodes for ultimate transmission to the base station.

The Power Efficient Gathering in Sensor Information System (PEGASIS) introduced by Lindsey and Raghavendra [15] aims at optimising the LEACH algorithm. Instead of organising the nodes as clusters, PEGASIS forms chains, using the greedy algorithm, with the sensor nodes. One of the nodes is designated in each round for communication with the sink. The chain structure in PEGASIS allows each node to transmit to and receive from only one of its closest neighbours. The data is aggregated with other data while travelling along the chain until ultimately reaching the base station. PEGASIS improves on energy utilisation of individual nodes. However, it faces the risk of having delayed data transmission and bottleneck of the relay node to the base station.

Lindsey and Raghavendra [15] proposed the hierarchical PEGASIS, H-PEGASIS, which improves on the transmission delay of PEGASIS, by considering the energy and delay metrics. H-PEGASIS allows simultaneous transmissions of data messages. H-PEGASIS caters for collisions and signal interference among sensor nodes by incorporating signal coding and allowing separated nodes to transmit data together. H-PEGASIS provides a hierarchical extension to PEGASIS with nodes chain forming a tree like hierarchy. H-PEGASIS allows nodes of a particular level to communicate to selected nodes in upper level of the hierarchy.

Yueyang, Hong and Guangxin [16] use a distance threshold in EB-PEGASIS to improve upon PEGASIS. EB-PEGASIS avoids long chain thus enhancing energy consumption of the nodes. In EB-PEGASIS, the nodes consider an average distance of a chain. If the distance from the closest node and the upstream nodes are longer than the distance threshold from each other, the closest node is considered a 'far node'. A long chain will thus result if the closest node joins the chain. The 'far node' may in this situation consider a nearer node on the chain. EB-PEGASIS saves nodes energy and improves lifetime of the network.

The HEED protocol as introduced by Younis and Fahmy [17] extends upon the LEACH protocol by considering the residual energy and the node density for cluster selection. The inception of HEED was based on four basic goals namely i) prolonging the network lifetime by distributing energy consumption, ii) stopping the clustering process within a number of iterations, iii) diminishing control overhead, and iv) producing well distributed cluster head and compact clusters. In HEED, the residual energy of sensor node and intra-cluster communication cost determine cluster head selection.

The Threshold Sensitive Energy Efficient Sensor Network Protocol (TEEN) is a protocol proposed by Manjeshwar and Agrawal [18] for reactive networks. Changes in the sensed attributes caused the nodes to react. In TEEN, cluster heads (CHs) communicate by forwarding a hard threshold value and a soft threshold value. The nodes sense the environment continuously. If an attribute parameter reaches the hard threshold value, the node reacts by switching on their transmitter and sending data. Data transmission is only possible if the sensed value exceeds the hard threshold and the current value of the sensed attribute differs from the stored sensed value data of the sensed value (SV) variable, by an amount equal to or greater than the soft threshold. TEEN aims mainly at reducing energy spent on data transmission and is suited for time critical data network. The hard threshold control transmission by allowing nodes to transmit only when the sensed attribute is within the range of interest. The soft threshold decreases transmission by eliminating transmission when there is insignificant change in the sensed attribute.

The Adaptive TEEN, APTEEN proposed by Manjeshwar and Agrawal [18] improves upon TEEN. In APTEEN, the best features of proactive and reactive networks are combined such that data are sent periodically and response to sudden attribute value changes is possible. The architecture of APTEEN is similar to that of TEEN, which allows hierarchical clustering for energy efficient communication between the source node and the destination node. Upon cluster formation, the $\mathrm{CHs}$ forward the attributes, which define the interest of the user, the thresholds, which control data transmissions, the TDMA schedule, and the maximum time period between two successive reports sent by a node. APTEEN supports data aggregation for improved energy efficiency. In APTEEN, user queries include historical queries for analysis of historical data stored at the base station, one-time query for current view of the network, and 
persistent query for continuously monitoring over a specific time interval with respect to some specified parameters.

Geographic Adaptive Fidelity (GAF) [19] optimize performance of wireless sensor networks by identifying equivalent nodes with respect to forwarding packets. In GAF protocol, the nodes use GPS location based information to situate themselves on a virtual grid. The master of the grid is the node with the highest residual energy. Nodes are considered equivalent if they maintain the same set of neighbours and as such share the same communication routes.

The Minimum Energy Communication Protocol, MECN proposed by Rodoplu and Meng [19], is essentially a location-based protocol adapted for maintaining a minimum energy network with randomly deployed mobile nodes. The MECN generates an optimal spanning tree, called the minimum power topology, with the sink as the root. The tree holds only the minimum power path of each node to the sink. MECN is based on the position of the sensors on the plane and is made up of two phases, namely the enclosure graph construction and the cost distribution.

SMECN proposed by $\mathrm{Li}$ and Halpern [20] improves on MECN by creating a sub network, which is more energy efficient in relaying. Compared to MECN the sub network created by SMECN for the same boundary is much smaller for the same set of nodes.

The Geographic and Energy Aware Routing (GEAR) [21] uses energy aware and geographically informed neighbour heuristics to route packer towards the destination. The nodes in GEAR keep an estimated cost and a learning cost of reaching the destination through neighbours. The estimated cost is a function of the residual energy and the distance to destination. The learned cost is an improvement over the estimated cost and accounts for routing around holes.

The Virtual Grid Architecture Routing (VGA) proposed by Al-Karaki and Kamal [22] is an energy efficient routing paradigm that maximises the network lifetime by using data aggregation and in-network processing. The network is divided into fixed, equal, adjacent and non-overlapping symmetric shaped clusters.

\section{Performance Metrics: Accuracy and Longevity}

Each routing protocol has its own uniqueness as well as similarity with other routing protocol. It is thus hard to conclude whether a particular routing protocol is better than another routing protocol since sensor networks are mostly scenario and application specific. Discussion will mainly be based on metrics.

In this paper, the metrics accuracy and longevity are considered to determine the efficiency of the different routing algorithms listed Section II.

We define Accuracy as to how accurate the routing protocols provide data and longevity as to how the routing protocols maintain the network alive either by either the first node death or by extending the overall time up to, which all nodes die.

Common methods used to prolong the network lifetime include reducing energy consumption. Topology control, general sleep/wakeup protocol, MAC protocols with low duty cycle and cross layer design [23].

Since maintaining accuracy and longevity together may be possible for a certain amount of time, we analyse this possibility. We extend our observation to cases whereby either accuracy or longevity may be sacrificed to ensure efficiency of the network. Finally we provide a trade-off between the two metrics.

\section{ANALYSIS}

The number of active nodes in a WSN deployment governs both the longevity of the network and the accuracy of applications using the network's data. In this work, we analyse the algorithms to demonstrate the trade-offs between the two metrics for a WSN.

Based on the longevity and accuracy analysis of WSN algorithms, it is observed that the algorithms in the different routing protocols classification favour longevity over accuracy. Moreover, improvement of most existing algorithms is focused on how to improve the longevity of existing protocols instead of the accuracy.

TABLE I: OBSERVATION OF FLAT ROUTING ALGORITHMS

\begin{tabular}{|c|c|c|c|}
\hline \multicolumn{4}{|c|}{ FLAT ROUTING } \\
\hline Algorithms & How Accuracy is ensured & How longevity is maintained & Analysis \\
\hline Directed Diffusion & $\begin{array}{l}\text { Two-way gradients allow the nodes to } \\
\text { receive copies of low data rate events from } \\
\text { each neighbour thereby enabling quick } \\
\text { recovery from path failure and } \\
\text { reinforcement of better paths. Source sends } \\
\text { high rate data to high gradient link along } \\
\text { reinforced paths. }\end{array}$ & $\begin{array}{l}\text { The application aware nodes } \\
\text { enable energy savings by selecting } \\
\text { empirically better paths and } \\
\text { enabling data aggregation. }\end{array}$ & $\begin{array}{l}\text { The algorithm favours empirically } \\
\text { better routes. Not all nodes contribute } \\
\text { to the data transmission to sink node. }\end{array}$ \\
\hline SPIN-PP & Uses the three-stage handshake protocol. & $\begin{array}{l}\text { The use of meta data reduces } \\
\text { implosion, overlapping and } \\
\text { resource blindness. }\end{array}$ & $\begin{array}{l}\text { The algorithm places emphasis on } \\
\text { increasing the network lifetime. In } \\
\text { event where the sink may be } \\
\text { interested with too many events, } \\
\text { quick energy depletion of } \\
\text { surrounding nodes is observed. } \\
\text { Moreover the data advertisement } \\
\text { mechanism does not guarantee the } \\
\text { delivery of data. }\end{array}$ \\
\hline SPIN-EC & Uses the three-stage handshake protocol. & $\begin{array}{l}\text { The energy conservation heuristic } \\
\text { controls the nodes participation in } \\
\text { data communication. }\end{array}$ & $\begin{array}{l}\text { The algorithm improves the overall } \\
\text { network lifetime. However, the data } \\
\text { advertisement mechanism does not } \\
\text { guarantee the delivery of data. }\end{array}$ \\
\hline
\end{tabular}




\begin{tabular}{|c|c|c|c|}
\hline SPIN-BC & Uses the three-stage handshake protocol. & Uses a single shared channel. & $\begin{array}{l}\text { The algorithm improves the overall } \\
\text { network lifetime. However, the data } \\
\text { advertisement mechanism does not } \\
\text { guarantee the delivery of data. }\end{array}$ \\
\hline SPIN-RL & $\begin{array}{l}\text { Uses the three-stage handshake protocol. } \\
\text { Ensures receipt of requested data. }\end{array}$ & $\begin{array}{l}\text { Restricts frequency } \text { between } \\
\text { sending and receiving. }\end{array}$ & $\begin{array}{l}\text { The algorithm improves the overall } \\
\text { network lifetime. However, the data } \\
\text { advertisement mechanism does not } \\
\text { guarantee the delivery of data. }\end{array}$ \\
\hline SPIN-M & Uses the three-stage handshake protocol. & $\begin{array}{l}\text { Includes distance discovery phase } \\
\text { to calculate distance of the nodes } \\
\text { to the sink. The nodes do not send } \\
\text { data to nodes that are further away } \\
\text { from sink than itself. }\end{array}$ & $\begin{array}{l}\text { The algorithm improves the overall } \\
\text { network lifetime. The algorithm } \\
\text { achieves energy saving by discarding } \\
\text { transmission to the opposite direction } \\
\text { of the sink node. However, the data } \\
\text { advertisement mechanism does not } \\
\text { guarantee the delivery of data. }\end{array}$ \\
\hline Rumor routing & $\begin{array}{l}\text { Uses agents that maintain list of the } \\
\text { recently visited nodes with possibility of } \\
\text { aggregating event history of other nodes. }\end{array}$ & $\begin{array}{l}\text { Maintains single walkthrough } \\
\text { path to event. }\end{array}$ & $\begin{array}{l}\text { The algorithm favours older events } \\
\text { because more paths are built for them. } \\
\text { The algorithm in most cases uses an } \\
\text { existing path to the event. Other } \\
\text { nodes that may as well be used to } \\
\text { reach the event may not be } \\
\text { considered. }\end{array}$ \\
\hline SER & $\begin{array}{l}\text { Uses different message types for task } \\
\text { execution. }\end{array}$ & $\begin{array}{l}\text { Takes into account the memory } \\
\text { limitation of sensor nodes, energy } \\
\text { of the nodes, and the QoS of the } \\
\text { instruction. }\end{array}$ & Strives to improve network lifetime. \\
\hline GBR & $\begin{array}{l}\text { Employs different data dissemination } \\
\text { techniques. }\end{array}$ & $\begin{array}{l}\text { Energy load balancing amongst } \\
\text { nodes is ensured through } \\
\text { aggregation and uniform traffic } \\
\text { spreading. Stochastic path } \\
\text { selection and spreading } \\
\text { techniques including energy based } \\
\text { and stream based adjustment to } \\
\text { height. }\end{array}$ & $\begin{array}{l}\text { Focuses on energy load balancing by } \\
\text { combining direct transmission and } \\
\text { multi-hop transmission. If a } \\
\text { forwarder node finds that its } \\
\text { neighbour has lower potential for } \\
\text { data transmission to the base station, } \\
\text { the forwarder node transmits the data } \\
\text { directly to the base station. }\end{array}$ \\
\hline COUGAR & $\begin{array}{l}\text { Lacks proper synchronisation among the } \\
\text { nodes for ultimate submission to the leader } \\
\text { nodes. Has a poor propagation condition, } \\
\text { which may lead to storage of erroneous } \\
\text { information in the nodes. }\end{array}$ & $\begin{array}{llr}\text { Performs } & \text { in-network } & \text { data } \\
\text { aggregation } & \text { to obtain } & \text { energy } \\
\text { savings. } & & \end{array}$ & $\begin{array}{l}\text { Some nodes though having data may } \\
\text { not cooperate in sending the data to } \\
\text { the base station. }\end{array}$ \\
\hline ACQUIRE & $\begin{array}{l}\text { Provides efficient querying by adjusting the } \\
\text { value of a look-ahead parameter. }\end{array}$ & $\begin{array}{l}\text { Uses a query mechanism and } \\
\text { progressively solved queries by } \\
\text { using cached information of } \\
\text { nodes. }\end{array}$ & $\begin{array}{l}\text { Resolved queries are returned } \\
\text { through shortest path to the sink. } \\
\text { Next node for query forwarding is } \\
\text { based on maximum potential of query } \\
\text { satisfaction. }\end{array}$ \\
\hline SAR & $\begin{array}{l}\text { Provides multipath approach and ensures } \\
\text { fault tolerance. }\end{array}$ & $\begin{array}{l}\text { Improves lifetime by minimizing } \\
\text { the average weighted QoS metric. } \\
\text { Energy resources, QoS planned } \\
\text { for each path and type of traffic } \\
\text { packet type are considered in } \\
\text { decision-making. }\end{array}$ & $\begin{array}{l}\text { Avoids nodes with low throughput or } \\
\text { high delay. }\end{array}$ \\
\hline EAR & Provides good throughput. & $\begin{array}{l}\text { Considers energy balance to } \\
\text { choose next hop. Route packets } \\
\text { mainly through larger remaining } \\
\text { energy nodes, neighbourhood } \\
\text { nodes with larger energy and } \\
\text { nodes with relatively less sensing } \\
\text { and data processing. }\end{array}$ & Low energy nodes ignored. \\
\hline
\end{tabular}

TABLE II: OBSERVATION OF HIERARCHICAL ROUTING ALGORITHMS

\begin{tabular}{|c|c|c|c|}
\hline \multicolumn{4}{|c|}{ HIERARCHICAL ROUTING } \\
\hline Algorithms & How Accuracy is ensured & How longevity is maintained & Analysis \\
\hline SHRP & $\begin{array}{l}\text { Uses unifying protocol for right } \\
\text { selection of neighbours. }\end{array}$ & $\begin{array}{l}\text { Load balancing for traffic } \\
\text { routing. } \\
\text { Best route detection is done, by } \\
\text { considering battery availability, } \\
\text { number of hops and link quality. }\end{array}$ & $\begin{array}{l}\text { Neighbouring nodes with average link } \\
\text { quality are cut off from the routing table. }\end{array}$ \\
\hline LEACH & $\begin{array}{l}\text { Cluster head nodes keep receiver on to } \\
\text { receive all data from the cluster. }\end{array}$ & $\begin{array}{l}\text { Periodic cluster head rotation } \\
\text { across network to balance energy } \\
\text { across the nodes. Data } \\
\text { aggregation to reduce } \\
\text { redundancy. }\end{array}$ & $\begin{array}{l}\text { In the case where there is a dead cluster } \\
\text { head, the cluster becomes useless and } \\
\text { data collected by nodes never reach the } \\
\text { base station. }\end{array}$ \\
\hline
\end{tabular}




\begin{tabular}{|c|c|c|c|}
\hline LEACH-C & $\begin{array}{l}\text { Nodes are aware of their location within } \\
\text { the network. }\end{array}$ & $\begin{array}{l}\text { Ensures uniform distribution of } \\
\text { the cluster heads. Takes into } \\
\text { account the amount of energy in } \\
\text { the node and whether or not the } \\
\text { node was recently a cluster head } \\
\text { node. }\end{array}$ & $\begin{array}{l}\text { Improve upon LEACH mainly by } \\
\text { extending the network lifetime. }\end{array}$ \\
\hline LEACH-F & $\begin{array}{l}\text { Cluster head node keep receiver on to } \\
\text { receive all data from the cluster. }\end{array}$ & $\begin{array}{l}\text { Decreases the cluster formation } \\
\text { overhead before each round. }\end{array}$ & $\begin{array}{l}\text { Does not cater for increasing, decreasing } \\
\text { and losing effect of sensor nodes. }\end{array}$ \\
\hline VLEACH & $\begin{array}{l}\text { Cluster head nodes gather data from the } \\
\text { normal nodes. }\end{array}$ & $\begin{array}{l}\text { Introduces vice cluster head } \\
\text { nodes that replace dying cluster } \\
\text { head nodes. }\end{array}$ & $\begin{array}{l}\text { Improved network lifetime compared to } \\
\text { LEACH. }\end{array}$ \\
\hline E-LEACH & $\begin{array}{l}\text { Cluster head nodes gather data from the } \\
\text { normal nodes. }\end{array}$ & $\begin{array}{l}\text { Cluster head selection is done } \\
\text { based on the energy level of } \\
\text { nodes. }\end{array}$ & $\begin{array}{l}\text { Improved network lifetime compared to } \\
\text { LEACH. }\end{array}$ \\
\hline TL-LEACH & $\begin{array}{l}\text { Cluster head nodes gather data from the } \\
\text { normal nodes. }\end{array}$ & $\begin{array}{l}\text { Uses two levels of clusters for } \\
\text { transmitting data to the base } \\
\text { station. }\end{array}$ & $\begin{array}{l}\text { Decreases the number of nodes that need } \\
\text { to transmit over long distance. }\end{array}$ \\
\hline M-LEACH & $\begin{array}{l}\text { Cluster head nodes gather data from the } \\
\text { normal nodes. }\end{array}$ & $\begin{array}{l}\text { Uses multi-hop communication } \\
\text { between the } \mathrm{CH} \text { and the BS. }\end{array}$ & Extends the network lifetime. \\
\hline LEACH-P & $\begin{array}{l}\text { Cluster head nodes and pseudo cluster } \\
\text { head node gather data from the normal } \\
\text { nodes. }\end{array}$ & $\begin{array}{l}\text { Uses a pseudo-cluster head node } \\
\text { to replace the } \mathrm{CH} \text { when it is } \\
\text { limited in energy. }\end{array}$ & $\begin{array}{l}\text { Enhance efficiency of energy utilisation } \\
\text { and extends the network lifetime. }\end{array}$ \\
\hline LEACH-L & $\begin{array}{l}\text { Cluster head nodes gather data from the } \\
\text { normal nodes }\end{array}$ & $\begin{array}{l}\mathrm{CH} \text { uses multi-hop } \\
\text { communication to the BS when it } \\
\text { is far from the } \mathrm{BS} \text { and uses direct } \\
\text { communication when it is near. }\end{array}$ & Extends the network lifetime. \\
\hline $\begin{array}{l}\text { Hierarchical } \\
\text { PEGASIS }\end{array}$ & $\begin{array}{l}\text { Cluster head nodes gather data from the } \\
\text { normal nodes }\end{array}$ & $\begin{array}{l}\text { Improves transmission delay of } \\
\text { PEGASIS by considering energy } \\
\text { and delay metrics. Nodes take } \\
\text { turn to transmit to the base } \\
\text { station thus reducing the average } \\
\text { energy spent by each node per } \\
\text { round. }\end{array}$ & Improves network lifetime. \\
\hline PEGASIS & $\begin{array}{l}\text { Based on assumption that all nodes } \\
\text { know the location of every other node. }\end{array}$ & $\begin{array}{l}\text { Uses the chain structure such that } \\
\text { each node transmits to and } \\
\text { receives from only one of its } \\
\text { closest neighbours. Improves on } \\
\text { energy utilisation of individual } \\
\text { nodes. }\end{array}$ & $\begin{array}{l}\text { Introduces too much delay for far-away } \\
\text { node on the chain. The single leader } \\
\text { node may cause bottleneck. }\end{array}$ \\
\hline EB PEGASIS & $\begin{array}{l}\text { Cluster head nodes gather data from the } \\
\text { normal nodes }\end{array}$ & $\begin{array}{l}\text { Improves on PEGASIS by using } \\
\text { distance threshold. Avoids long } \\
\text { chain thus balancing energy } \\
\text { consumption of nodes. }\end{array}$ & Extends the network lifetime. \\
\hline HEED & $\begin{array}{l}\text { Coordination between the different } \\
\text { cluster heads. }\end{array}$ & $\begin{array}{l}\text { Improves upon LEACH by } \\
\text { considering residual energy and } \\
\text { node density for cluster } \\
\text { selection. }\end{array}$ & $\begin{array}{l}\text { Aims mainly at improved network } \\
\text { lifetime. }\end{array}$ \\
\hline TEEN & $\begin{array}{l}\text { Controlled data transmission based on } \\
\text { threshold. }\end{array}$ & $\begin{array}{l}\text { Conserves energy of nodes by } \\
\text { switching off sensors at all times } \\
\text { except at report times. }\end{array}$ & $\begin{array}{l}\text { In periodic reporting user may not get } \\
\text { data at all if the values of the attributes } \\
\text { do not reach the threshold. }\end{array}$ \\
\hline APTEEN & $\begin{array}{l}\text { Aims at capturing periodic data and } \\
\text { responding to time critical events. }\end{array}$ & $\begin{array}{l}\text { Ensures energy efficient } \\
\text { communication between source } \\
\text { and destination node. }\end{array}$ & $\begin{array}{l}\text { Includes overhead in cluster formation } \\
\text { at multiple level. }\end{array}$ \\
\hline GAF & $\begin{array}{l}\text { Nodes within a virtual grid may reach } \\
\text { any node in an adjacent virtual grid. }\end{array}$ & $\begin{array}{l}\text { Enables energy conservation by } \\
\text { identifying equivalent routing } \\
\text { nodes and turning unnecessary } \\
\text { nodes off. Achieves load } \\
\text { balancing through periodic } \\
\text { re-election of the leader. }\end{array}$ & $\begin{array}{l}\text { In some cases all nodes may be in the } \\
\text { sleeping states and no packets } \\
\text { forwarded. }\end{array}$ \\
\hline GEAR & $\begin{array}{l}\text { Uses Geographical Information System } \\
\text { to find location of sensor nodes in the } \\
\text { network. }\end{array}$ & $\begin{array}{lr}\text { Uses energy aware and } \\
\text { geographically } & \text { informed } \\
\text { neighbour selection heuristics to } \\
\text { route packets. }\end{array}$ & $\begin{array}{l}\text { When a node does not have any close } \\
\text { neighbour towards the target region, a } \\
\text { hole occurs. }\end{array}$ \\
\hline
\end{tabular}

TABLE III: OBSERVATION OF ADAPTIVE ROUTING ALGORITHMS. ADAPTIVE ROUTING

\begin{tabular}{|c|c|c|c|}
\hline \multicolumn{4}{|c|}{ ADAPTIVE ROUTING } \\
\hline Algorithms & How Accuracy is ensured & How longevity is maintained & Analysis \\
\hline MECN & $\begin{array}{l}\text { Network assumed to be fully } \\
\text { connected }\end{array}$ & $\begin{array}{l}\text { Makes use of an optimal spanning tree, which holds } \\
\text { only the minimum power path of each node to the sink. } \\
\text { Makes use of relay region for every node such that } \\
\text { transmission through nodes in the relay region is more } \\
\text { energy efficient. Utilises low power GPS to maintain a } \\
\text { low energy network. }\end{array}$ & $\begin{array}{l}\text { Reduces power in communication } \\
\text { between nodes by finding } \\
\text { sub-network with fewer nodes for } \\
\text { communication. }\end{array}$ \\
\hline
\end{tabular}




\begin{tabular}{|c|l|l|l|}
\hline SMECN & $\begin{array}{l}\text { Provides improvement over } \\
\text { MECN by considering } \\
\text { obstacles between any pair of } \\
\text { nodes. }\end{array}$ & $\begin{array}{l}\text { Improves upon MECN by maintaining a sub- network, } \\
\text { which is more energy efficient. The sub-network } \\
\text { favours sending of messages on minimum energy paths. }\end{array}$ & $\begin{array}{l}\text { The sub-network in SMECN is } \\
\text { smaller than in MECN for more } \\
\text { energy efficient communication. }\end{array}$ \\
\hline
\end{tabular}

The basis of the SPIN family of protocols is negotiation and resource adaptation. The SPIN protocols cut down mainly on activities when energy is low. In cases where there are too many requests from the sink node, the surrounding nodes quickly deplete their energy resulting into holes. Improvement in the SPIN protocol aims mainly at improving the network lifetime compared to classic data flooding. SPIN-PP reduces the energy consumption considerably by using negotiation. SPIN-EC provides improvement by using a threshold based resource awareness mechanism together with negotiation consequently improving the overall lifetime. In SPIN-EC, a node does not initiate the request if it does not have enough energy to complete the request transmit and data reception steps. Following this concept in SPIN-EC, it is observed that the algorithm proceeds ignoring the particular node with limited energy for data transmission. SPIN-RL caters for accuracy in a way by successfully recovering packet-loss and decreases the energy consumption compared to flooding. The SPIN family of protocols consider the two basic ideas in operation: perform efficiently and conserving energy. The sensors communicate with each other to check for data that they already have and data that they still need. Though sensor data communication may be expensive in terms of energy, exchanging data about sensor data is not as expensive. Moreover, the nodes in the network need to monitor and adapt to changes in their respective energy resources to extend the lifetime of the network.

The SAR algorithms favours some nodes over others based on their energy efficiency. Low energy nodes are ignored. In the EAR protocol as well, the low energy nodes are often ignored.

In the LEACH protocol, in the event of a cluster head failure the data collected by the cluster head never reaches the base station, which is synonymous to having all the nodes in that cluster off or dead [24]. Most of the algorithms that improve on the LEACH protocols try mainly to extend the network lifetime. LEACH-C includes a deterministic threshold algorithm, which caters for the energy of the node. LEACH-C algorithm increases the time before the first node death and the time for the nodes to decrease by half the initial amount. LEACH-F improves LEACH, by enhancing the cluster formation overhead of LEACH such that once cluster heads are determined, the $\mathrm{CH}$ remained fixed. LEACH-F improves LEACH in terms of longevity and at the expense of accuracy. Increasing, decreasing and losing effect of sensor nodes are not catered for. VLEACH introduces a vice cluster head node to replace the cluster head node when it dies thus keep the cluster alive for a longer period of time. E-LEACH provides improvement over LEACH mainly by extending the network's lifetime. E-LEACH considers the energy level of nodes for cluster head selection. Through the addition of another level in the cluster, the TL-LEACH improves upon the LEACH protocol by decreasing the energy consumption and consequently increasing the lifetime of the network. The M-LEACH protocol improves the LEACH protocol in view of extending the network lifetime. Instead of using the single hop present in LEACH, M-LEACH adopts multi-hop communication between the $\mathrm{CH}$ and the BS. LEACH-L protocol considers the communication distance between the $\mathrm{CH}$ and the $\mathrm{BS}$. When the $\mathrm{CH}$ node is close to the base station, it communicates directly to the BS. When it is far it uses multi-hop communication to the base station. The added modification brought to LEACH-L is mainly to increase the network lifetime by retaining the energy of the $\mathrm{CH}$, which is located far from the BS.

The PEGASIS protocol outperforms the LEACH protocol by excluding the overhead implied with dynamic cluster formation, minimising the distance normal nodes need for data transmission, reducing the number of transmissions and receipts among the nodes and by using only one node for transmission to the BS within each round. The hierarchical PEGASIS and EB-PEGASIS both improve on PEGASIS so as to make it more energy efficient and consequently extending the network lifetime.

In TEEN though effectiveness is achieved through the concept of using threshold to determine which data to transmit, in cases where the values of attributes do not reach the threshold, data may not reach the user at all. In GAF, all nodes within a particular virtual grid are equivalent for routing, and only one node need to be active. In the situation where all nodes remain in the sleeping states no data may be collected since no packets are forwarded. Though GEAR ensures longevity and accuracy to some extent, holes are frequent when there are no close neighbour nodes to the target region.

The greatest accuracy in all cases are expected to be reached when all the nodes contribute in collection of data and when all the data collected are forwarded to the base stations and used in processing. However, in most cases, concession on accuracy is done in one way or the other as specified in the above tables.

\section{CONCLUSION}

In this paper we have analysed the trade-off between accuracy and longevity in some common routing protocols. Most of the routing protocols analysed strive to preserve both accuracy and longevity. However, in the event that one of the two parameters needs to be sacrificed, accuracy is in one-way or the other penalized. We conclude that though both the parameters are crucial for the proper running of a wireless sensor network, longevity is the most required parameter because if the network is no longer alive, no data about the network will be available. A less accurate data is favoured compared to no data at all.

\section{REFERENCES}

[1] J. N. Al-Karaki and A. E. Kamal, "Routing techniques in wireless sensor networks: A survey," Wireless Communications, IEEE, vol. 11, no. 6, pp. 6-28, 2004.

[2] D. Estrin, R. Gobindan, J. Heidemann, and S. Kumar, "Next century challenges: Scalable coordination in sensor networks," in Proc. $5^{\text {th }}$ 
Annual ACM/IEEE International Conference on Mobile Computing and Networking, New York, USA, 1999, pp. 263-270.

[3] W. R. Heinzelman, J. Kulik, and H. Balakrishnan, "Adaptive protocols for information dissemination in wireless sensor networks," in Proc. $5^{\text {th }}$ Annual ACM/IEEE International Conference on Mobile Computing and Networking, Washington, USA, 1999, pp. 174-185.

[4] Z. Rehena, S. Roy, and N. Mukherjee, "A modified SPIN for wireless sensor networks," in Proc. The Third International Conference on Communication Systems and Networks, Bangalore, India, 2011, pp. $1-4$.

[5] D. Braginsky and D. Estrin, "Rumor routing algorithm for sensor networks," in Proc. $1^{\text {st }}$ Workshop on Sensor Networks and Applications, Atlanta, 2002, pp. 22-31.

[6] W. Su and I. F. Akyildiz, "A stream enabled routing (SER) protocol for sensor networks," in Proc. The Annual Mediterranean Ad Hoc Networking Workshop, Italy, 2002.

[7] O. Powell, A. Jarry, P. Leone, and J. D. P. Rolim, "Gradient based routing in wireless sensor networks: A mixed strategy," Computing Research Repository of Distributed, Parallel and Cluster Computing, 2008.

[8] Y. Yao and J. Gehrke, "The cougar approach to in-network query processing in sensor networks," Newsletter, ACM SIGMOD Record, vol. 31, no. 2, pp. 9-18, 2002.

[9] N. Sadagopan, B. Krishnamachari, and A. Helmy, "The ACQUIRE mechanism for efficient querying in sensor networks," in Proc. $1^{\text {st }}$ IEEE International Workshop on Sensor Network Protocols and Applications, Anchorage, USA, 2003, pp. 149-155.

[10] D. De, W.-Z. Song, and D. Cook, "EAR: An energy and activity aware routing protocol for wireless sensor networks in smart environments," The Computer Journal, vol. 55, pp. 1492-1506, 2012.

[11] C. J. B. Abbas, R. González, N. Cardenas, and L. J. García Villalba, "A proposal of a wireless sensor network routing protocol,' Telecommunication Systems, vol. 38, no. 1/2, pp. 61-68, 2008.

[12] J. Polastre, J. Hui, P. Levis, J. Zhao, D. Culler, S. Shenker, and I. Stoica, "A unifying link abstraction for wireless sensor networks," in Proc. $3^{\text {rd }}$ International Conference on Embedded Networked Sensor Systems, San Diego, CA, USA, 2005, pp. 76-89.

[13] L. Shan, J. Zhang, G. Zhou, L. Gu, J. A. Stankovic, and T. He, "ATPC: Adaptive transmission power control for wireless sensor networks," in Proc. $4^{\text {th }}$ International Conference on Embedded Networked Sensor Systems, ACM, USA, 2006, pp. 223-236.

[14] W. R. Heinzelman, A. Chandrakasan, and H. Balakrishnan, "Energy-efficient communication protocol for wireless microsensor networks," in Proc. $33^{\text {rd }}$ Annual Hawaii International Conference on System Sciences, Hawaii, USA, 2000, p. 8020.

[15] S. Lindsey and C. S. Raghavendra, "PEGASIS: Power-efficient gathering in sensor information systems," in Proc. IEEE Aerospace Conference, Big Sky, USA, 2002, pp. 1125-1130.
[16] L. Yueyang, J. Hong, and Y. Guangxin, "An energy-efficient PEGASIS-based enhanced algorithm in wireless sensor networks," Technical Report, DCN Lab, Beijing University of Posts and Telecommunications, Beijing, China, 2006.

[17] O. Younis and S. Fahmy, "Distributed clustering in ad-hoc sensor networks: A hybrid, energy-efficient approach," in Proc. $23^{\text {rd }}$ Annual Joint Conference of the IEEE Computer and Communications Societies, Hong Kong, 2004.

[18] A. Manjeshwar and D. P. Agrawal, "TEEN: A routing protocol for enhanced efficiency in wireless sensor networks," in Proc. $15^{\text {th }}$ International Parallel and Distributed Processing Symposium, San Francisco, USA, 2001, pp. 2009-2015.

[19] V. Rodoplu and T. H. Meng, "Minimum energy mobile wireless networks," IEEE Journal on Selected Areas in Communications, vol. 17, no. 8, pp. 1333-1344, 1999.

[20] L. Li and J. Y. Halpern, "Minimum-energy mobile wireless networks revisited," in Proc. IEEE International Conference on Communications, Finland, 2001, pp. 278-283.

[21] Y. Yu, R. Govindan, and D. Estrin, "Geographical and energy aware routing: a recursive data dissemination protocol for wireless sensor networks," Technical Report, UCLA Computer Science Department, UCLA-CSD TR-01-0023.

[22] J. N. Al-Karaki and A. E. Kamal, "Efficient virtual-backbone routing in mobile ad hoc networks," The International Journal of Computer and Telecommunications Networking, vol. 52, no. 2, pp. 327-350, 2008.

[23] G. Anastasi, M. Conti, M. Di Francesco, and A. Passarella, How to Prolong the Lifetime of Wireless Sensor Network, Handbook of Mobile Ad Hoc and Pervasive Communications, American Scientific Publishers, 2006.

[24] M. Malik and Y. Singh, "Analysis of LEACH protocol in wireless sensor networks," International Journal of Advanced Research in Computer science and Software Engineering, vol. 3, no. 2, pp. $178-183,2013$

Nassirah Laloo received the BEng (Hons) degree computer science and engineering from the University of Mauritius in 2003. She obtained a master degree with distinction in computer science and engineering in 2006. She is currently working as a lecturer at the University of Technology, Mauritius. She is from the Department of Industrial Systems Engineering at the School of Innovative Technologies and Engineering.

Mohammad Sameer Sunhaloo received the BSc (Hons) degree in mathematics from the University of Mauritius in 1999. He obtained his $\mathrm{PhD}$ degree in computational mathematics in 2006 . He is currently the head of the School of Innovative Technologies and Engineering at the University of Technology Mauritius. 